\title{
Isolated spontaneous dissection of the celiac trunk in a patient with bicuspid aortic valve
}

\author{
This article was published in the following Dove Press journal: \\ Vascular Health and Risk Management \\ 15 May 2010 \\ Number of times this article has been viewed
}

\author{
Abdel-Rauf Zeina' \\ Alicia Nachtigal' \\ Anton Troitsa ${ }^{2}$ \\ Gil Admon ${ }^{2}$ \\ Nina Avshovich ${ }^{3}$ \\ 'Department of Radiology, \\ ${ }^{2}$ Department of Surgery A, \\ ${ }^{3}$ Department of Internal Medicine C, \\ Hillel Yaffe Medical Center, Hadera, \\ Israel. Hillel Yaffe Medical Center \\ is affiliated with the Faculty of \\ Medicine, Technion - Israel Institute \\ of Technology, Haifa, Israel
}

\begin{abstract}
Isolated spontaneous dissection of celiac trunk is a rare entity. The spontaneous dissection of the visceral artery occurs without aortic dissection. The most consistent presenting symptom is acute onset abdominal pain. Complications consist of ischemia, aneurysm formation, and rupture. We report an exceptional case of an isolated spontaneous dissection of the celiac trunk which occurred in a 49 year old male with a previously undiagnosed bicuspid aortic valve (BAV). We also describe the classical appearance in different imaging modalities with a particular emphasis on multidetector computed tomography, and discuss the clinical manifestation and its relationship to BAV.

Keywords: celiac trunk dissection, isolated spontaneous dissection, CT angiography, bicuspid aortic valve, MRA
\end{abstract}

\section{Case report}

A 49-year-old male was admitted to the emergency department at Hillel Yaffe Medical Center, Hadera, Israel, with sudden onset epigastric pain associated with nausea. The pain was sharp, constant, and radiating to his back. He had not experienced fevers, vomiting, diarrhea, or a history of abdominal trauma. At presentation, the patient had unremarkable vital signs. He had a history of long-term medication-controlled hypertension and was a smoker. His physical examination revealed diffuse tenderness in the mid-abdomen and epigastrium. Chest radiograph and plain films of the abdomen were normal. For further evaluation, a contrast-enhanced computed tomography (CT) of the abdomen using a 64-slice multidetector computed tomography 64-(MDCT) instrument (Brilliance-64, Philips Healthcare, Haifa, Israel) was performed. The CT scan revealed an intimal flap in the celiac trunk causing moderate vessel narrowing, with aneurysmal formation, mural thrombus, and increased attenuation of the surrounding fat. An extension of the dissection from the celiac trunk into the proximal hepatic artery was also identified (Figures 1-2). The abdominal aorta, the superior and inferior mesenteric and renal arteries were intact. Such CT findings are compatible with the diagnosis of isolated spontaneous dissection of the celiac trunk. Additional CT findings were a small splenic artery aneurysm and a right kidney hypodense cortical area consistent with renal infarction (Figure 3).

The patient was then transferred to the vascular surgery unit for medical treatment and follow-up. He was started on steroids and Clexane ${ }^{\circledR}$, and had an uneventful hospital course. While in the hospital, the patient underwent an extensive rheumatological evaluation that showed only a mild elevation of C-reactive protein (CRP), with no other serologic evidence to support the presence of vasculitis or an inflammatory disorder. A gallium
Correspondence:Abdel-Rauf Zeina Department of Radiology, Hillel Yaffe Medical Center, P.O.B. 169,

Hadera 38100, Israel

Tel +972-4-630462I

Fax +972-4-6304884

Email raufzeina3@hotmail.com;

raufzeina@yahoo.com 
A

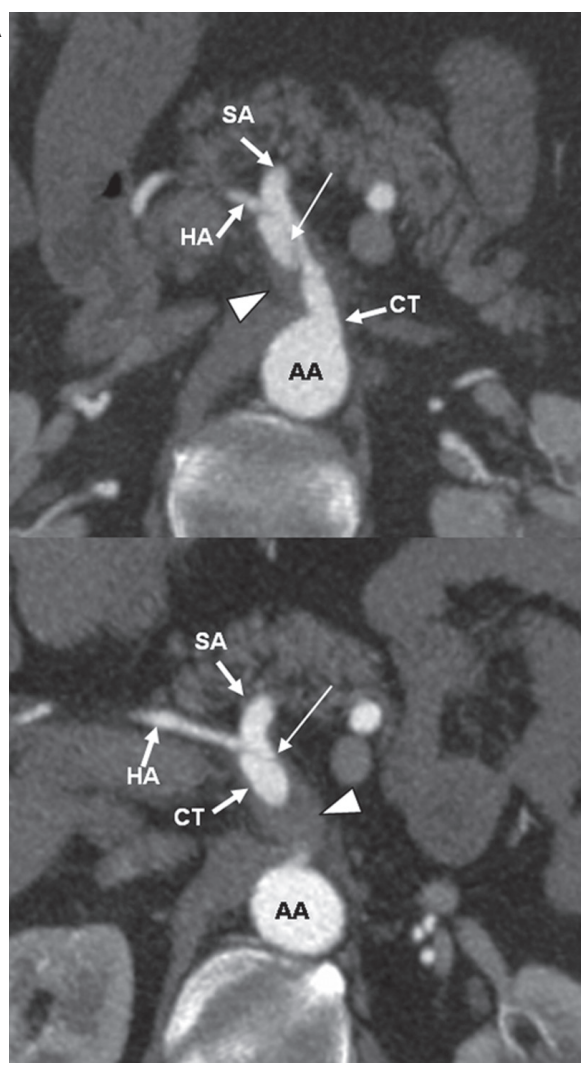

B

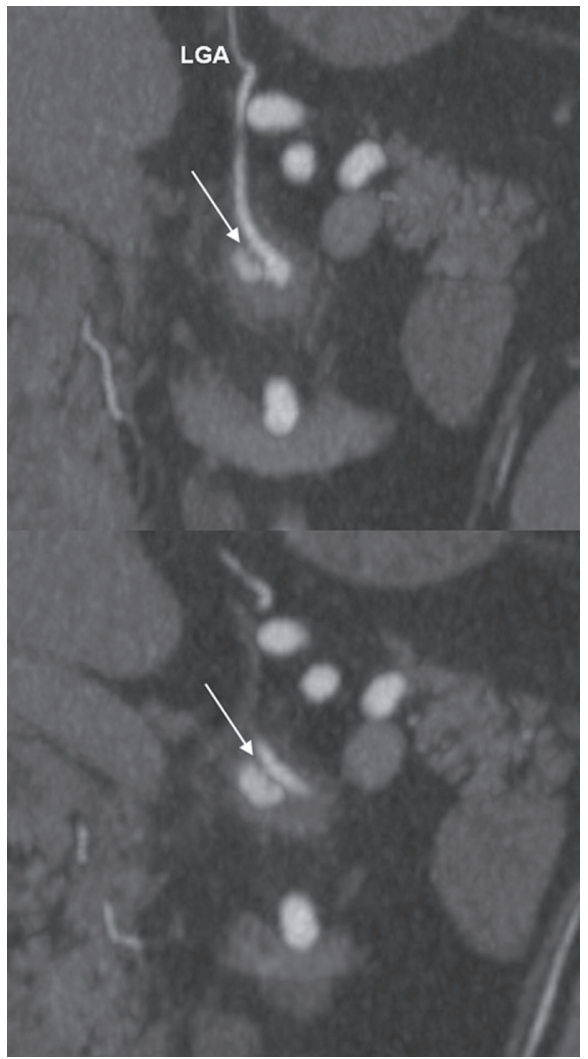

Figure I A) Axial contrast-enhanced computed tomography scan through upper abdomen shows an intimal flap (arrow) in the celiac trunk (CT) causing moderate vessel narrowing, with aneurysmal formation, mural thrombus (arrowhead), and increased attenuation of the surrounding fat. Findings are consistent with celiac artery dissection. The abdominal aorta (AA) is intact. HA denotes hepatic artery; SA denotes splenic artery. B) Coronal reformatted computed tomography images show the celiac artery dissection (arrow) with associated thrombus involving false lumen. LGA denotes left gastric artery.
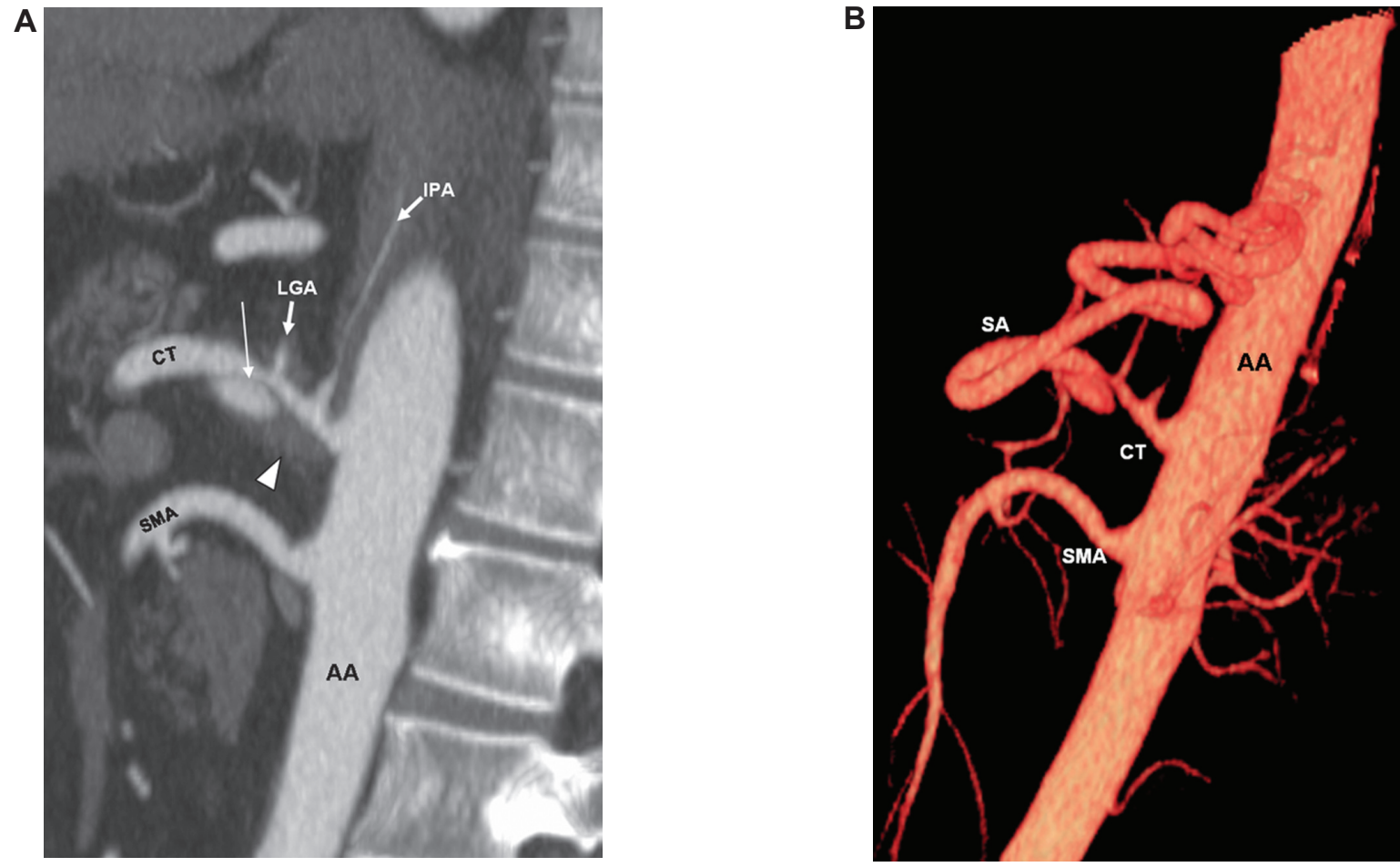

Figure 2 A) Contrast-enhanced sagittal reformatted computed tomography image shows celiac trunk (CT) dissection (arrow) with associated aneurysmal formation and thrombus (arrowhead) involving the false lumen. B) Three-dimensional volume-rendered reformatted image shows narrowing of proximal celiac trunk (CT), which represents true lumen. AA denotes abdominal aorta; IPA denotes inferior phrenic artery; LGA denotes left gastric artery; SMA denotes superior mesenteric artery. 

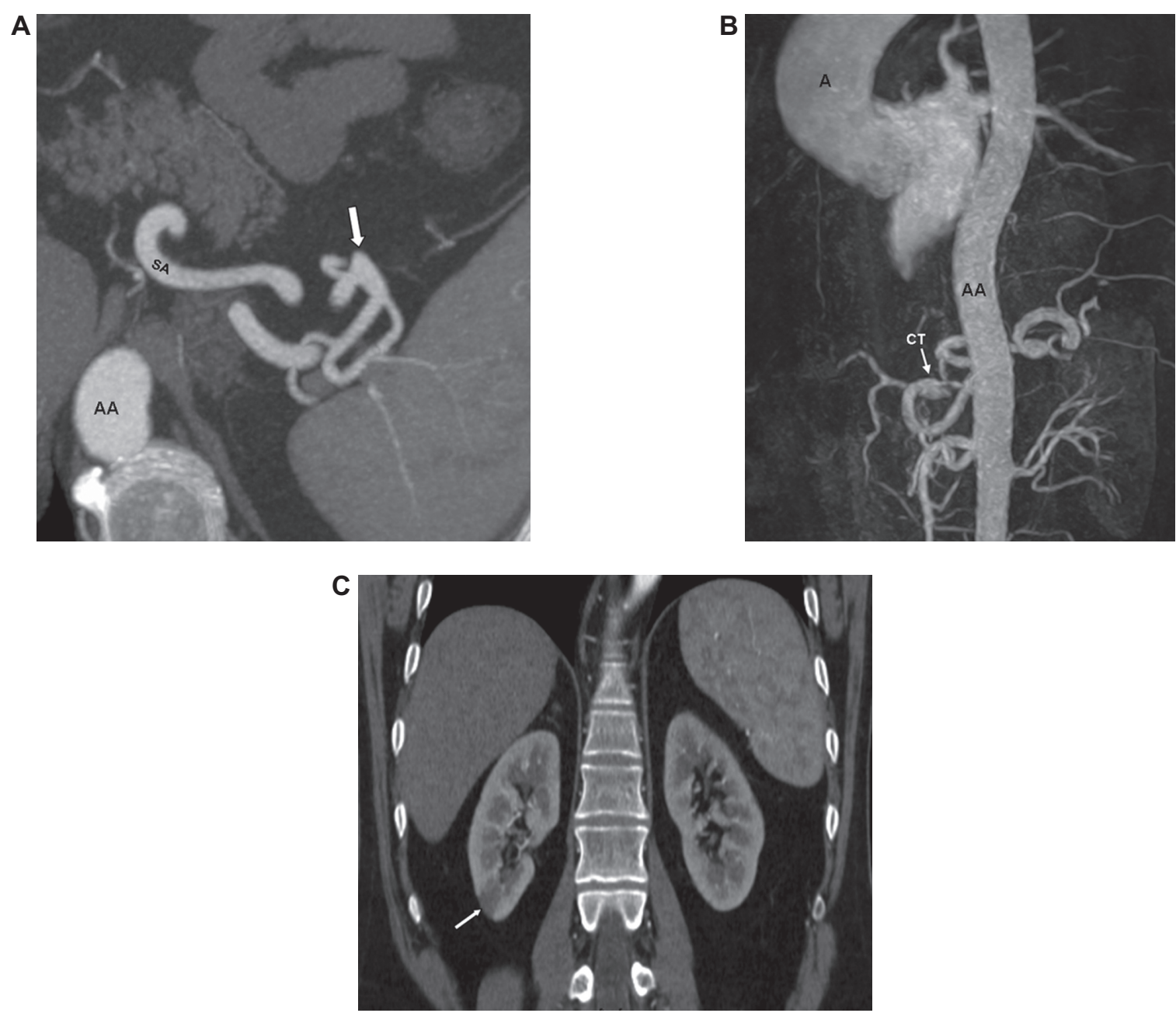

Figure 3 A) Axial contrast-enhanced computed tomography scan through upper abdomen shows a small aneurysm (arrow) of the splenic artery (SA). B) Magnetic resonance angiography (MRA) image showing celiac trunk dissection (CT) and an ascending aorta (A) dilatation of $4.9 \mathrm{~cm}$. Normal widely patent abdominal aorta (AA) shows no evidence of dissection. C) Coronal reformatted computed tomography image shows right renal infarct (arrow).

scan revealed no evidence of active infection or inflammatory process. A follow-up scan using magnetic resonance imaging (MRI) and magnetic resonance angiography (MRA), at three weeks, showed persistent celiac trunk dissection and an ascending aorta dilatation of $4.9 \mathrm{~cm}$ (Figure 3). The patient therefore underwent transesophageal echocardiography (TEE) for further structural and functional cardiac evaluation. The TEE confirmed the diagnosis of ascending aorta dilatation and revealed a previously undiagnosed bicuspid aortic valve (BAV) associated with mild aortic regurgitation (Figure 4). In the follow-up period, the patient's abdominal pain was relieved to some extent with conservative therapy (steroids and Clexane ${ }^{\circledR}$ ), but was not completely resolved.

\section{Discussion}

Isolated spontaneous dissection of the celiac trunk is uncommon and rarely considered in patients with acute abdominal pain. However, this condition has been reported more frequently in recent years. ${ }^{1-5}$ The spontaneous dissection occurs without aortic dissection. To our knowledge, this is the first reported case of spontaneous celiac artery dissection to be diagnosed in a patient with BAV. The most consistent presenting symptom is acute onset abdominal pain. Risk factors include hypertension, atherosclerosis, fibromuscular dysplasia, cystic medial necrosis, trauma, pregnancy, infection, and vasculitis (such as Takayasu arteritis, polyarteritis nodosa, giant cell arteritis). ${ }^{1}$ However, no definite pathologic cause for the dissection was identified in most reported cases. Complications may include visceral ischemia, aneurysmal formation, rupture, and propagation of the dissection to adjacent visceral arteries. The prognosis depends on the degree of stenosis of the involved segment and the presence or absence of such complications. The cause of spontaneous dissection in our patient was not identified but hypertension has been linked to 
A

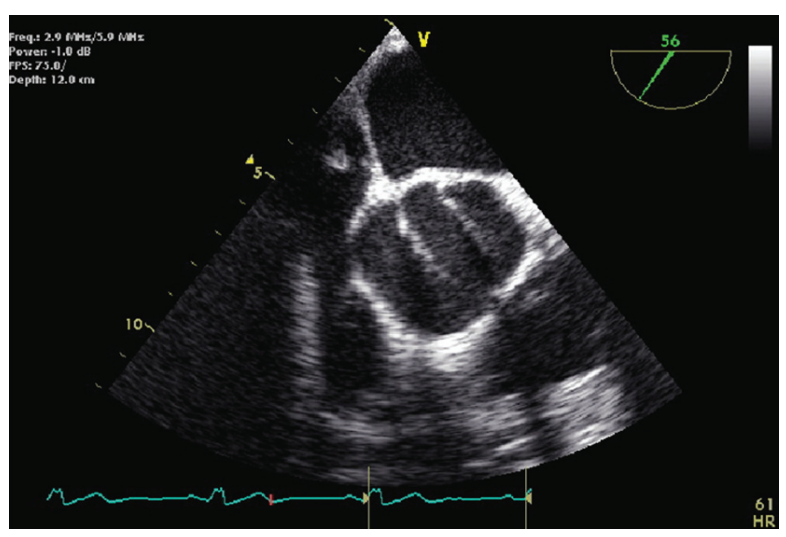

B

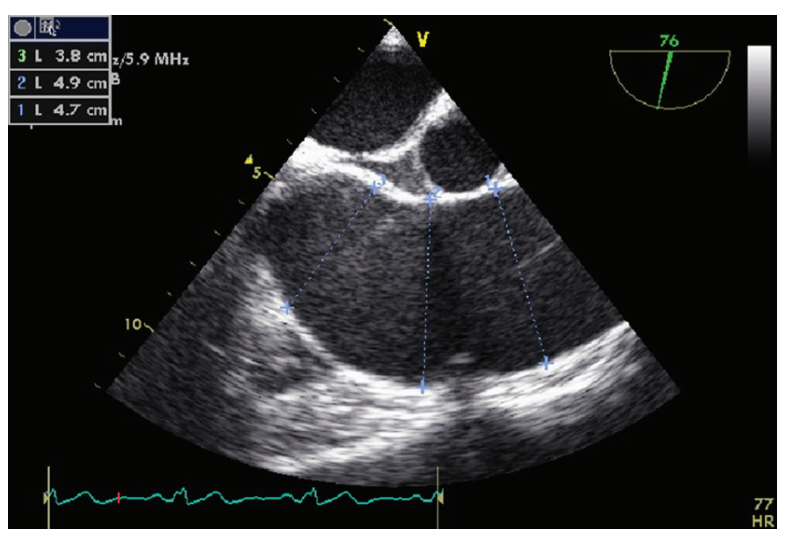

Figure 4 Transesophageal echocardiography (TEE) images show the bicuspid aortic valve $\mathbf{A}$ ) and the ascending aorta dilatation B).

this abnormality. The presence of a BAV is an independent risk factor for progressive aortic dilation, aneurysm formation, and dissection. BAV is associated with accelerated degeneration of the aortic media that may be responsible for the various visceral artery abnormalities detected in our patient. Researchers ${ }^{6}$ have identified focal abnormalities within the aortic media of patients with BAV, such as matrix disruption and smooth muscle cell loss, suggesting a degenerative process that may result in structural weakness of the aortic wall. The presence of celiac trunk dissection with ascending aorta aneurysm, splenic artery aneurysm, and right kidney infarction in the same patient indicates a systemic rather than local disease.

Contrast-enhanced CT is considered the primary technique for diagnosing celiac artery dissection; however, MRI/MRA, Doppler ultrasound, and conventional angiography can also be used. Diagnostic imaging findings on contrast-enhanced CT include an intimal flap, mural thrombus with or without aneurysmal dilatation, celiac trunk segmental stenosis, and infiltration of the fat surrounding the vessel. Although several treatment options are available, researchers have not come to a consensus regarding guidelines for the proper management of an isolated spontaneous dissection of the celiac trunk. Medical therapy should include anticoagulant or anti-platelet agents to prevent thromboembolic complications, and blood pressure control to prevent progression of the dissection plane. Conservative treatment with steroids has been also reported as a treatment option. Surgical or endovascular treatment may be reserved for symptomatic patients despite medical treatment and those with complicated diseases (ie, aneurysm formation, ischemia, or rupture). ${ }^{7}$

Although once believed rare, isolated spontaneous celiac trunk dissection should be considered in the differential diagnosis of acute abdominal pain, particularly in patients with congenital disorders causing arterial wall weakening, as was the case for our patient.

\section{Disclosures}

The authors report no conflicts of interest in this work.

\section{References}

1. D'Ambrosio N, Friedman B, Siegel D, Katz D, Newatia A, Hines J. Spontaneous isolated dissection of the celiac artery: CT findings in adults. Am J Roentgenol. 2007;188:506-511.

2. Takayama T, Miyata T, Shirakawa M, Nagawa H. Isolated spontaneous dissection of the splanchnic arteries. J Vasc Surg. 2008;48:329-333.

3. Wang JL, Hsieh MJ, Lee CH, Chen CC, Hsieh IC. Celiac artery dissection presenting with abdominal and chest pain. Am J Emerg Med. 2010;28:111.e3-e5.

4. Glehen O, Feugier P, Aleksic Y, Delannoy P, Chevalier JM. Spontaneous dissection of the celiac artery. Ann Vasc Surg. 2001;15:687-692.

5. Nordanstig J, Gerdes H, Kocy H. Spontaneous isolated dissection of the celiac trunk with rupture of the proximal splenic artery: a case report. Eur J Vasc Endovasc Surg. 2009;37:194-197.

6. Fedak PW, Verma S, David TE, Leask RL, Weisel RD, Butany J. Clinical and pathophysiological implications of a bicuspid aortic valve. Circulation. 2002;20:900-904.

7. Fenoglio L, Allione A, Scalabrino E, et al. Spontaneous dissection of the celiac artery: a pitfall in the diagnosis of acute abdominal pain presentation of two cases. Dig Dis Sci. 2004;49:1223-1227.
Vascular Health and Risk Management

\section{Publish your work in this journal}

Vascular Health and Risk Management is an international, peerreviewed journal of therapeutics and risk management, focusing on concise rapid reporting of clinical studies on the processes involved in the maintenance of vascular health; the monitoring, prevention and treatment of vascular disease and its sequelae; and the involvement of

\section{Dovepress}

metabolic disorders, particularly diabetes. This journal is indexed on PubMed Central and MedLine. The manuscript management system is completely online and includes a very quick and fair peer-review system, which is all easy to use. Visit http://www.dovepress.com/ testimonials.php to read real quotes from published authors. 